\title{
Lomustine and temozolomide for newly diagnosed glioblastoma with methylated MGMT promoter: Lessons from the CeTeG/NOA- 09 trial
}

\author{
Ivo W. Tremont-Lukats ${ }^{1}$, Bin S. Teh ${ }^{2}$ \\ ${ }^{1}$ The Kenneth R. Peak Center for Pituitary and Brain Tumors, Houston Methodist Hospital, Houston, TX, USA; ${ }^{2}$ Department of Radiation \\ Oncology, Houston Methodist Hospital, Cancer Center and Research Institute, Houston, TX, USA \\ Correspondence to: Ivo W. Tremont-Lukats, MD. 6445 Main St., Outpatient Center, Floor 24, Houston, TX 77030, USA. \\ Email: itremont@houstonmethodist.org. \\ Comment on: Herrlinger U, Tzaridis T, Mack F, et al. Lomustine-temozolomide combination therapy versus standard temozolomide therapy in \\ patients with newly diagnosed glioblastoma with methylated MGMT promoter (CeTeG/NOA-09): a randomised, open-label, phase 3 trial. Lancet \\ 2019;393:678-88.
}

Submitted Jun 05, 2019. Accepted for publication Jun 20, 2019.

doi: $10.21037 /$ tcr.2019.06.43

View this article at: http://dx.doi.org/10.21037/tcr.2019.06.43

The Neuro-Oncology Working Group of the German Cancer Society (Neuroonkologische Arbeitsgemeinshaft, NOA), studied the effect of lomustine (CCNU, 1-(2-chloroethyl)3-cyclohexyl-1-nitrosourea) and temozolomide together to treat patients with newly diagnosed glioblastoma with a methylated $\mathrm{O}^{6}$-methylguanine DNA methyltransferase (MGMT) promoter (1). This strategy needed testing after the encouraging results of a phase II trial (2), and the synergistic or additive effect between temozolomide and lomustine since nitrosoureas have additional non-alkylating effects on DNA and cell replication (3).

To adequately present the context and relevance of this research, it is necessary to summarize its methods. CeTeG/NOA-09 (Ce: CeeCNU, an initial brand name for lomustine; Te: for temozolomide, G: glioblastoma; NOA-09 indicates the cooperative group and the inception year), was a multicenter, open-label, phase III study with random allocation. Masking was not possible because of the treatment sequences between the investigational and the control groups. The participants were patients aged 1870 years with newly diagnosed, untreated glioblastoma with methylated MGMT promoter who had biopsy or tumor resection and a Karnofsky performance score (KPS) of $70 \%$ or higher. The inclusion and exclusion criteria were well outlined, and the ethics committees of all participating centers approved the trial. Patients were allocated randomly $1: 1$ by a software-generated randomization list at a designated center to a control group (concurrent temozolomide at $75 \mathrm{mg} / \mathrm{m}^{2}$ daily and conformal radiation therapy $\times 6$ weeks for a total dose of 59-60 Gy, followed by adjuvant temozolomide at $150-200 \mathrm{mg} / \mathrm{m}^{2} \times 5 \mathrm{~d}$ every $28 \mathrm{~d} \times 6$ cycles), or to the investigational group, which began the first cycle of lomustine $100 \mathrm{mg} / \mathrm{m}^{2}$ on day 1 and temozolomide $100 \mathrm{mg} / \mathrm{m}^{2}$ on days 2-6 of radiation therapy $\times 6$ weeks for a total dose of 59-60 Gy and repeated this schedule every 6 weeks $\times 6$ cycles. Dose adjustments were based on toxicity, evaluations were clearly specified and radiographic responses were assessed with slightly modified Response Assessment in Neuro-Oncology (RANO) criteria.

With a modified intention to treat, the primary endpoint was overall survival (OS) from the day of allocation. The study had several secondary endpoints but for our commentary we will limit discussion on progression-free survival (PFS) and hematological toxicity. The statistical methods were solid and rational, addressing sample size with assumptions derived from 2-year survival rates of previous NOA studies and other assumptions necessary to establish sample size with $80 \%$ power to achieve a statistical significance at $\mathrm{P}=0.05$. The trial sponsorship was governmental, not industry-based.

One hundred forty-one participants were randomized; 63 patients were in the control group and 66 in the investigational group, most of them with good KPS and subtotal or grossly complete resections. The group treated 
Table 1 Relevant outcomes in critically appraised topic

\begin{tabular}{lcccccc}
\hline Outcome & Time of outcome & CER & EER & RRR (95\% Cl) & ARR (95\% Cl) & NNT or NNH \\
\hline OS & 5 years & 0.86 & 0.64 & $25 \%(9 \%$ to $41 \%)$ & $0.22 \%(0.08 \%$ to $0.36 \%)$ & 5 \\
PFS & 5 years & 0.88 & 0.65 & $25 \%(9 \%$ to $41 \%)$ & $0.22 \%(0.08 \%$ to $0.35 \%)$ & 5 \\
Grade 3-4 hematological toxicity & NA & 0.50 & 0.62 & $26 \%(-7 \%$ to $59 \%)$ & $0.13 \%(-0.04 \%$ to $0.30 \%)$ & 8 \\
\hline
\end{tabular}

OS, overall survival; PFS, progression-free survival; CER, control event rate; EER, experimental event rate; RRR, relative risk reduction; ARR, absolute risk reduction; NNT, number needed to treat; $\mathrm{NNH}$, number needed to harm; $95 \% \mathrm{Cl}, 95 \%$ confidence interval.

with temozolomide and lomustine survived a median of 48 months, about 15 months more than the control patients $(\mathrm{P}=0.049)$, for a hazard ratio of $0.60,95 \%$ CI: $0.35-1.03$; log rank $\mathrm{P}=0.06)$. There was no difference in PFS between both groups. Nearly $60 \%$ of patients treated with temozolomide and lomustine and 50\% in the control group had grade 3 or higher toxicity. The authors concluded that "overall survival was significantly improved in the lomustine-temozolomide group compared with that of the temozolomide group", with well tolerated toxicity.

The essential question in CeTeG/NOA-09 is whether the difference in OS is solid enough to persuade us into changing or modifying the standard of care. There are several reasons why the answer should be a "no". First, the difference on OS barely made the level of significance. Mathematically we could call it a success, but a reduction in relative risk widely scattered from 0.35 to 1.03 is tantalizing. This observation is reinforced by the discrepancy between the PFS and the OS, which the authors discussed appropriately as a weakness along with a smaller-thanplanned sample size. This problem with size arose when some of the prognostic factors (sex, center, and RPA class) were not well-balanced as expected for a study with random allocation. In the unstratified analysis, there was simply no difference in OS. These flaws were pointed out by van den Bent at the $13^{\text {th }}$ congress of the European Association of Neuro-Oncology before final publication of the trial and by Stupp in a commentary $(4,5)$.

As an exercise, we assessed the CeTeG/NOA-09 using a critically appraised topic (CAT) model (6). The analysis yielded two observations of practical importance; one, that relative risk reductions can be misleading; two, that the absolute risk reduction is probably closer to the truth when estimating a treatment effect size (see Table 1).

The second reason important to us as clinicians against a change of treatment paradigm is toxicity. In the study, lomustine and temozolomide had a $7 \%$ higher rate of grade
3-4 hematologic toxicity than the standard of care; yet $60 \%$ of patients receiving the standard of care completed all 6 cycles of temozolomide treatment, whereas 39\% could complete therapy in the lomustine-temozolomide group. The probability of delay by cycle 5 was $40 \%$ among patients taking lomustine-temozolomide and only $17 \%$ in the standard of care. These data suggest that the lomustinetemozolomide combination was more toxic and less tolerated than the authors concluded. In this aspect, the CAT was not useful to us because information on delays and dose reductions was not included.

In summary, CeTeG/NOA-09 is an example of a welldesigned and executed study based on sound preclinical and clinical premises, with results that from a best evidence standpoint suggest that the combination of lomustinetemozolomide failed to meet expectations. We think of it as a negative trial with no additive therapeutic effect from combining two alkylating agents plus the additional toxicity due to partially redundant mechanisms of action.

Using the 5-year OS and PFS data to estimate the event rates for both groups and derive the ARR and RRR, the interpretation of results could vary by metric; if we wanted to persuade the audience that the study was a success, we could state that the intervention reduced the risk of death by $25 \%$. If we chose to be skeptical, the reduction in absolute risk $(0.22 \%)$ was unimpressive. What interpretation is correct? The 2- and 3-year event control rates (not shown) gave slightly different results in the same direction. Thus, this case illustrates the quagmire of interpreting results of studies well-conceived, planned and executed with the shortcomings of real life. It seems clear that the RRR is misleading, and that the ARR was more informative and in tune with reality.

\section{Acknowledgments}

Funding: None. 


\section{Footnote}

Provenance and Peer Review: This article is commissioned and reviewed by the Section Editor Xian-Xin Qiu [MD, $\mathrm{PhD}$ candidate, Shanghai Proton and Heavy Ion Center (SPHIC), a.k.a. the Proton and Heavy Ion Center of Fudan University Shanghai Cancer Center (FUSCC), Shanghai, China].

Conflicts of Interest: Both authors have completed the ICMJE uniform disclosure form (available at http://dx.doi. org/10.21037/tcr.2019.06.43). The authors have no conflicts of interest to declare.

Ethical Statement: The authors are accountable for all aspects of the work in ensuring that questions related to the accuracy or integrity of any part of the work are appropriately investigated and resolved.

Open Access Statement: This is an Open Access article distributed in accordance with the Creative Commons Attribution-NonCommercial-NoDerivs 4.0 International License (CC BY-NC-ND 4.0), which permits the noncommercial replication and distribution of the article with the strict proviso that no changes or edits are made and the original work is properly cited (including links to both the formal publication through the relevant DOI and the license). See: https://creativecommons.org/licenses/by-nc-nd/4.0/.

\section{References}

1. Herrlinger $\mathrm{U}$, Tzaridis T, Mack F, et al. Lomustinetemozolomide combination therapy versus standard temozolomide therapy in patients with newly diagnosed glioblastoma with methylated MGMT promoter (CeTeG/ NOA-09): a randomised, open-label, phase 3 trial. Lancet 2019;393:678-88.

2. Herrlinger U, Rieger J, Koch D, et al. Phase II trial of lomustine plus temozolomide chemotherapy in addition to radiotherapy in newly diagnosed glioblastoma: UKT-03.J Clin Oncol 2006;24:4412-7.

3. Lea MA. Effects of carbamoylating agents on tumor metabolism. Crit Rev Oncol Hematol 1987;7:329-71.

4. Van den Bent MJ. Adult glioma: Updates on clinic. EANO 2018 Educational Syllabus. Stockholm: European Association of Neuro-Oncology; 2018:16-23.

5. Stupp R. Drug development for glioma: are we repeating the same mistakes? Lancet Oncol 2019;20:10-2.

6. Sackett DL. How to practice and teach EBM. 2nd ed. In: Sackett DL, Strauss SE, Richardson WS, et al. editors. Evidence Based Medicine. Toronto: Churchill Livingstone; 2000:87-8.
Cite this article as: Tremont-Lukats IW, Teh BS. Lomustine and temozolomide for newly diagnosed glioblastoma with methylated MGMT promoter: Lessons from the CeTeG/ NOA-09 trial. Transl Cancer Res 2019;8(Suppl 6):S589-S591. doi: $10.21037 /$ tcr.2019.06.43 